\title{
Correlation of cumulus gene expression of GJA1, PRSS35, PTX3, and SERPINE2 with oocyte maturation, fertilization, and embryo development
}

\author{
Sheng-Hsiang Li $i^{1,2,3}$, Ming-Huei Lin ${ }^{1,2,4}$, Yuh-Ming Hwu ${ }^{1,4,5}$, Chung-Hao Lư ${ }^{4}$, Ling-Yu Yeh', Ying-Jie Chen ${ }^{4}$
} and Robert Kuo-Kuang Lee Le, $^{1,6^{*}}$

\begin{abstract}
Background: GJA1 and PTX3 were proposed as gene markers for oocyte and embryo developmental competence, while SERPINE2 was reported to be associated with pregnancy outcome. PRSS35, which is exclusively expressed in the ovary, may be correlated with oocyte competence. This study was conducted to evaluate the correlation of cumulus GJA1, PRSS35, PTX3, and SERPINE2 gene expression levels with oocyte maturation, fertilization, and early embryo development.

Methods: In total, 308 cumulus cell samples separated from individual cumulus-oocyte complex were obtained from 40 patients undergoing the intracytoplasmic sperm injection treatment procedure. Gene expression levels (mRNA levels) in cumulus cells were assessed using quantitative real-time polymerase chain reaction.

Results: Gene expression levels of GJA1 and SERPINE2 in cumulus cells surrounding mature oocytes were significantly lower than those in cumulus cells enclosing immature oocytes. PRSS35 mRNA levels in cumulus cells of fertilized oocytes were significantly higher than those in cumulus cells of unfertilized oocytes. GJA1 and SERPINE2 seemed to express higher mRNA levels, while PRSS35 showed lower expression in cumulus cells of oocytes that developed into embryos with good morphology; however, the expression levels of all three genes and PTX3 showed no significant differences between embryos with good or poor morphology.
\end{abstract}

Conclusions: GJA1 and SERPINE2 represent potential gene markers associated with oocyte maturation. PRSS35 may be correlated with oocyte fertilization potential. However, GJA1, PRSS35, PTX3, and SERPINE2 may not be considered as marker genes for predicting embryo morphology.

Keywords: Gene expression, Oocyte, Cumulus cells, Embryo development

\section{Background}

Oocytes secrete paracrine factors such as growth differentiation factor 9 and bone morphogenetic protein 15, which affect the gene expression of cumulus cells, thereby leading to cumulus expansion $[1,2]$. Cumulus expansion involves hyaluronan accumulation in the intercellular space of cumulus cells [3], and the structural integrity of the

\footnotetext{
* Correspondence: Ish@mmh.org.tw

'Department of Medical Research, Mackay Memorial Hospital, Tamsui District, New Taipei City 251, Taiwan

${ }^{4}$ Department of Obstetrics and Gynecology, Mackay Memorial Hospital,

Taipei City 104, Taiwan

Full list of author information is available at the end of the article
}

cumulus cell extracellular matrix (ECM) is essential for oocyte maturation. Several cumulus proteins linked to ECM hyaluronan, including pentraxin-3 (PTX3) $[4,5]$, are required for cumulus integrity, thereby ensuring cumulus expansion and oocyte maturation. In addition, nutrients and metabolites are transported through gap junctions between the oocyte and cumulus cells [6]. Taken together, bidirectional intercellular communication between oocytes and their surrounding cumulus cells is essential for the development of an egg that is competent to undergo fertilization and embryo development $[3,7,8]$. 
Cumulus cells gene expression may reflect oocyte maturation and competence. Numerous studies have been conducted to profile cumulus gene expression, identify gene markers, and predict oocyte or embryo competence [9-11]. The expression of potential marker genes in cumulus cells has been suggested to be associated with oocyte competence [10-14], embryo quality [9, 15-17], pregnancy outcome $[9,18,19]$, and live birth [20].

GJA1, also known as connexin 43, is the major gap junction protein that is expressed in cumulus granulosa cells, participating in connexons with other cumulus granulosa cells or the oocyte. GJA4, corresponding to connexin 37, appears to be the only connexin synthesized by the oocyte; it forms a heterologous gap junction with granulosa cells [6]. Loss-of-function of GJA4 interferes with the development of antral follicles [21, 22] and can be rescued by replacement with GJA1 [23]. GJA1 has been identified as a gene marker for oocyte fertilization potential and embryo quality $[16,17]$.

PTX3 gene expression in cumulus cells was also associated with oocyte/embryo competence and was a potentially reliable predictor of embryo developmental competence [14].

Proteases play an important role in the proteolysis process and are essential for tissue remodeling and functions of the ovary in which extensive tissue remodeling during folliculogenesis and ovulation take place. SERPINE2 mRNA levels in granulosa cells have been suggested to be a potential pregnancy biomarker [18]. Higher SERPINE2 expression levels were detected in cumulus cells of human immature oocytes than in those of mature oocytes [24, 25]. PRSS35 belongs to the trypsin class of serine proteases. This protease is exclusively expressed in the mouse ovary, suggesting that Prss 35 is involved in ovarian functions [26].

In the present study, we focused on the four cumulusexpressed genes GJA1, PRSS35, PTX3, and SERPINE2 and evaluated whether their expression levels correlate with oocyte maturation, fertilization, and embryo development in humans.

\section{Methods}

\section{Patients and cumulus cell collection}

Patients $(n=40)$ undergoing intracytoplasmic sperm injection (ICSI) treatments at the Center of Reproductive Medicine, Mackay Memorial Hospital, Taiwan received controlled ovarian hyperstimulation using the gonadotropin-releasing hormone antagonist protocol as described previously [27]. All patients were younger than 38 years. The number of oocytes retrieved per patient was larger than 5. Sperm samples collected from patients with the following criteria were excluded from the study: sperm counts $\leq 100,000 / \mathrm{ml}$, sperm motility $\leq 10 \%$, and sperm with normal morphology $<1 \%$. Patients with oocyte fertilization rates $<30 \%$ in the previous ICSI treatments were also excluded. This study was approved by the Mackay Memorial Hospital Institutional Review Board (reference number 09MMHIS024), and written consent for the use of human cumulus cells was obtained.

The cumulus-oocyte complexes (COCs) in antral follicles with a diameter larger than $14 \mathrm{~mm}$ were collected using transvaginal ultrasound and a 16-gauge needle and were exposed to 80 IU hyaluronidase in Quinn's Advantage Fertilization medium (Sage BioPharma, Bedminster, $\mathrm{NJ}$ ) for $20 \mathrm{~s}$ at $37^{\circ} \mathrm{C}$ to dissolve hyaluronan. The cumulus cells were individually collected from COCs under an Olympus SZX7 stereomicroscope (Tokyo, Japan). In total, 308 COCs were collected. The classification of cumulus cell samples is shown in Fig. 1. Samples were mixed with $20 \mu \mathrm{l}$ of extraction buffer from the Arcturus PicoPure RNA Isolation Kit (Applied Biosystems, Foster City, CA) for total RNA isolation and stored at $-80{ }^{\circ} \mathrm{C}$ until use.

\section{Assessment of oocyte maturity, fertilization, and embryo quality}

Oocytes with the first polar body extrusion were defined as mature oocytes; otherwise, they were defined as immature oocytes. Fertilization was assessed by the presence of two pronuclei and two polar bodies at $16-20 \mathrm{~h}$ (day 1) after ICSI. Embryos were morphologically graded on the basis of the degree of cellular fragmentation and the regularity of blastomere size. The day 3 embryo quality scoring system, modified from previous reports [28, 29], was used to grade the embryo as follows: grade 1, evensized blastomeres with no cytoplasmic fragmentation; grade 2, even-sized blastomeres with minor cytoplasmic fragmentation $\leq 20 \%$ of the embryo surface; grade 3, uneven-sized blastomeres with variable fragmentation; grade 4, even-or uneven-sized blastomeres with moderate to significant cytoplasmic fragmentation $>20 \%$ of the embryo surface; and grade 5 , few blastomeres of any size and severe fragmentation $\geq 50 \%$ of the embryo surface. Grade 1-2 embryos were considered to be good quality embryos, while grade $3-5$ embryos were considered to be poorquality embryos.

Total RNA extraction, cDNA synthesis, and quantitative real-time polymerase chain reaction (qPCR)

Total RNA of cumulus cells collected from a single COC was extracted using the Arcturus PicoPure RNA Isolation Kit and directly reverse transcribed into a $20 \mu \mathrm{l}$ firststrand cDNA pool using the High Capacity cDNA Archive Kit (Applied Biosystems) according to the manufacturer's instructions. qPCR was performed in a total volume of $20 \mu \mathrm{l}$, containing equally distributed cDNA, $250 \mathrm{nM}$ each of the forward and reverse primers (Table 1), and $10 \mu \mathrm{l}$ of $2 \times$ SYBR Green Master Mix (Applied Biosystems). All reactions were performed in triplicate and run on the $\mathrm{ABI} /$ 


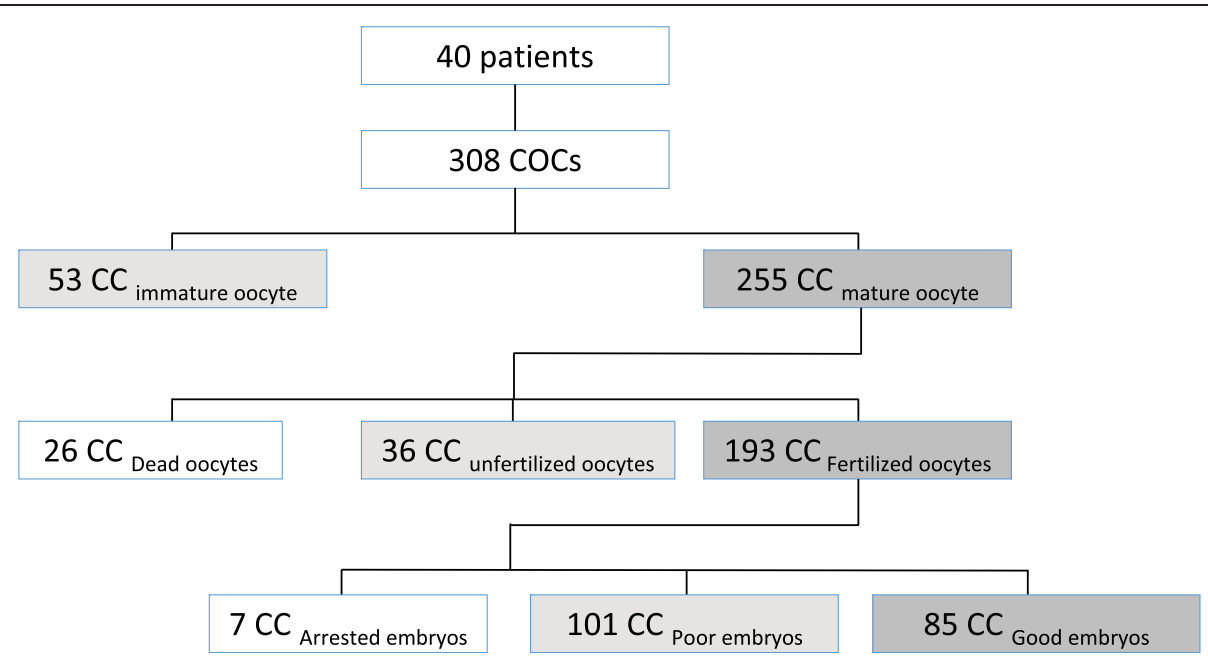

Fig. 1 Classification of cumulus cell samples used in this study. In total, 308 cumulus-oocyte complex (COC) samples were collected from 40 patients who underwent the ICSI procedure. Fertilized oocytes were cultured to day 3, and the early embryo morphology was assessed as described in "Materials and Methods". CC indicates the cumulus cells

PRISM 7500 Fast Sequence Detection System (Applied Biosystems) under the following conditions: $95{ }^{\circ} \mathrm{C}$ for $20 \mathrm{~s}$, followed by 40 cycles at $95^{\circ} \mathrm{C}$ for $1 \mathrm{~s}$ and $60{ }^{\circ} \mathrm{C}$ for $20 \mathrm{~s}$. The PCR amplification efficiency of each tested gene was pretested to ensure that it was equivalent to that of the housekeeping gene examined in a cDNA dilution series. The threshold cycle $(\mathrm{Ct})$ was defined as the fractional cycle number at which the reporter fluorescence that is the number of amplified copies reached a fixed threshold. Melting curve analysis was performed in order to verify that only a single product had formed in the reaction. DNA sequencing was performed to confirm the identity of PCR products. Relative quantification of mRNA expression was calculated using the $2^{-\Delta \Delta \mathrm{Ct}}$ method [30]. The housekeeping gene RPL19, encoding ribosomal protein L19, was used as the internal loading control to normalize the relative gene expression levels as it was validated as a suitable reference gene [31].

\section{Statistical analysis}

The nonparametric Mann-Whitney test was used for data analysis to compare the variables between two independent groups without normal distribution. The median value of each dataset is shown. $P$ values of $<0.05$ were considered significantly different. GraphPad Prism 5 (San Diego, CA) was used for all analyses.

\section{Results}

We measured the gene expression levels of GJA1, PRSS35, PTX3, and SERPINE2 in cumulus cells collected from a single COC. We also recorded oocyte maturity status, fertilization outcome of oocytes after ICSI, and morphology of day 3 embryos developed from fertilized oocytes. Statistical analyses were performed to evaluate the correlations between gene expression levels and oocyte maturation, fertilization, and embryo development.

Table 1 Summary of real-time PCR primers

\begin{tabular}{|c|c|c|c|}
\hline Gene name & GenBank accession no. & Primer sequence (5' to $\left.3^{\prime}\right)$ & Product size (bp) \\
\hline \multirow[t]{2}{*}{ GJA1 } & NM_000165 & $F^{a}:$ AGCAGTCTGCCTTTCGTTGTAAC & 94 \\
\hline & & $\mathrm{R}^{\mathrm{b}}:$ ACCCAGAAGCGCACATGAG & \\
\hline \multirow[t]{2}{*}{ PRSS35 } & NM_001170423.1 & F: ATTTGCCTCTGGATTCACGG & 110 \\
\hline & & R: CGGTAAGCAGAGCTGGTTTTCT & \\
\hline \multirow[t]{2}{*}{ PTX3 } & NM_002852.3 & F: TCCATCCCACTGAGGACCC & 102 \\
\hline & & R: TGCGCTCTCTCATCTGCG & \\
\hline \multirow[t]{2}{*}{ SERPINE2 } & NM_001136528 & F: TCTCATTGCAAGATCATCGCC & 97 \\
\hline & & R: CCCCATGAATAACACAGCACC & \\
\hline \multirow[t]{2}{*}{ RPL19 } & NM_000981 & F: TCGATCGCCACATGTATCACAG & 93 \\
\hline & & R: TCAGCTTGTGGATGTGTTCCA & \\
\hline
\end{tabular}

${ }^{a} F$, forward primer; ${ }^{b} R$, reverse primer 
GJA1 and SERPINE2 mRNA levels in cumulus cells correlated with oocyte maturation

Cumulus cells surrounding mature oocytes expressed significantly lower mRNA levels of GJA1 and SERPINE2 than those from immature oocytes $(P=0.0034$ and $P=0.0002$, respectively). On the other hand, PRSS35 and PTX3 mRNA levels did not show significant differences (Fig. 2).

\section{Cumulus-expressed PRSS35 mRNA levels correlated with fertilization}

Cumulus cells collected from fertilized mature oocytes seemed to express higher mRNA levels of GJA1, PRSS35, PTX3, and SERPINE2 than those collected from unfertilized oocytes; however, only PRSS35 showed significant expression levels ( $P=0.0188$, Fig. 3$)$.

\section{GJA1, PRSS35, PTX3, and SERPINE2 expression levels were} not significantly different between embryos with good and poor morphology

It seemed that GJA1 and SERPINE2 were expressed at higher mRNA levels and PRSS35 was expressed at lower mRNA levels in cumulus cells encircling mature oocytes developing into high-quality embryos (grades 1 and 2) than in cumulus cells encircling mature oocytes developing into poor-quality embryos (grades 3-5); however, the difference was not statistically significant (Fig. 4a, b, and d). There was no difference in PTX3 expression (Fig. 4c).

\section{Discussion}

GJA1-mediated gap junctional communication regulates oocyte meiosis resumption, and lower levels of GJA1 in cumulus cells are beneficial for oocyte maturation [32]. Our data showed that there was significantly lower expression of GJA1 in cumulus cells of mature oocytes than in those of immature oocytes. Feuerstein et al. reported a similar result [12]; however, no difference was found in a study with a relatively smaller sample size [16].

GJA1 mRNA levels in cumulus cells showed no significant differences between fertilized and unfertilized oocytes (Fig. 3), in line with the results reported by Hasegawa et al. [16]. GJA1 expression in cumulus cells surrounding the mature oocytes did not show any difference in developing embryos with good or poor morphology (Fig. 4), as reported previously [12]; however, significantly lower expression was also reported for embryos with good morphology [16]. Intriguingly, while GJA1 expression in cumulus cells enclosing oocytes achieving blastocyst development showed significantly lower levels than that in cumulus cells enclosing oocytes unable to develop to blastocyst stage [12], its expression in cumulus cells
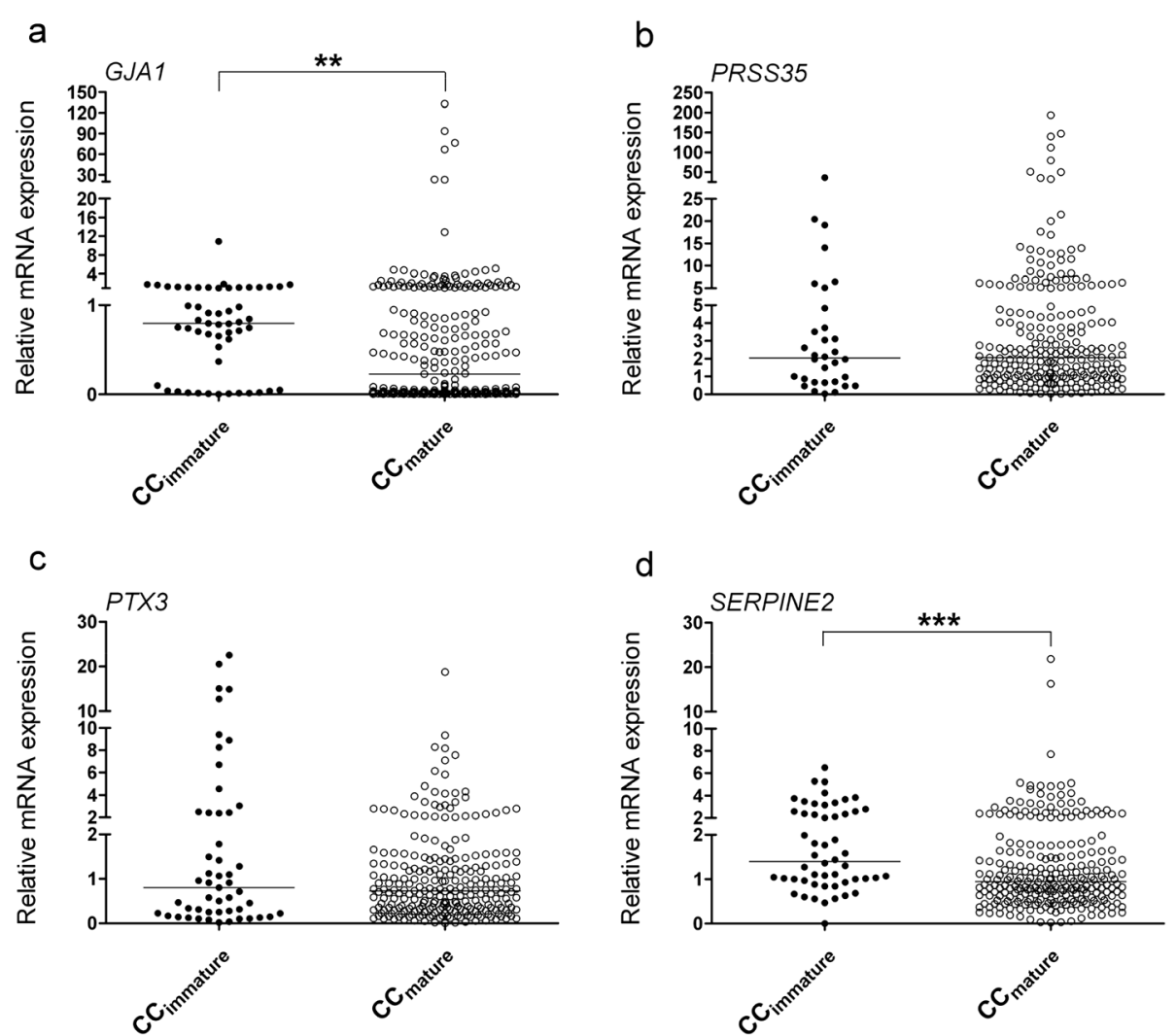

Fig. 2 qRT-PCR revealed relative mRNA levels of GJA1 (a), PRSS35 (b), PTX3 (c), and SERPINE2 (d) in cumulus cells surrounding immature or mature oocytes. ${ }^{* *} P<0.01 ;{ }^{* *} P<0.001$ 

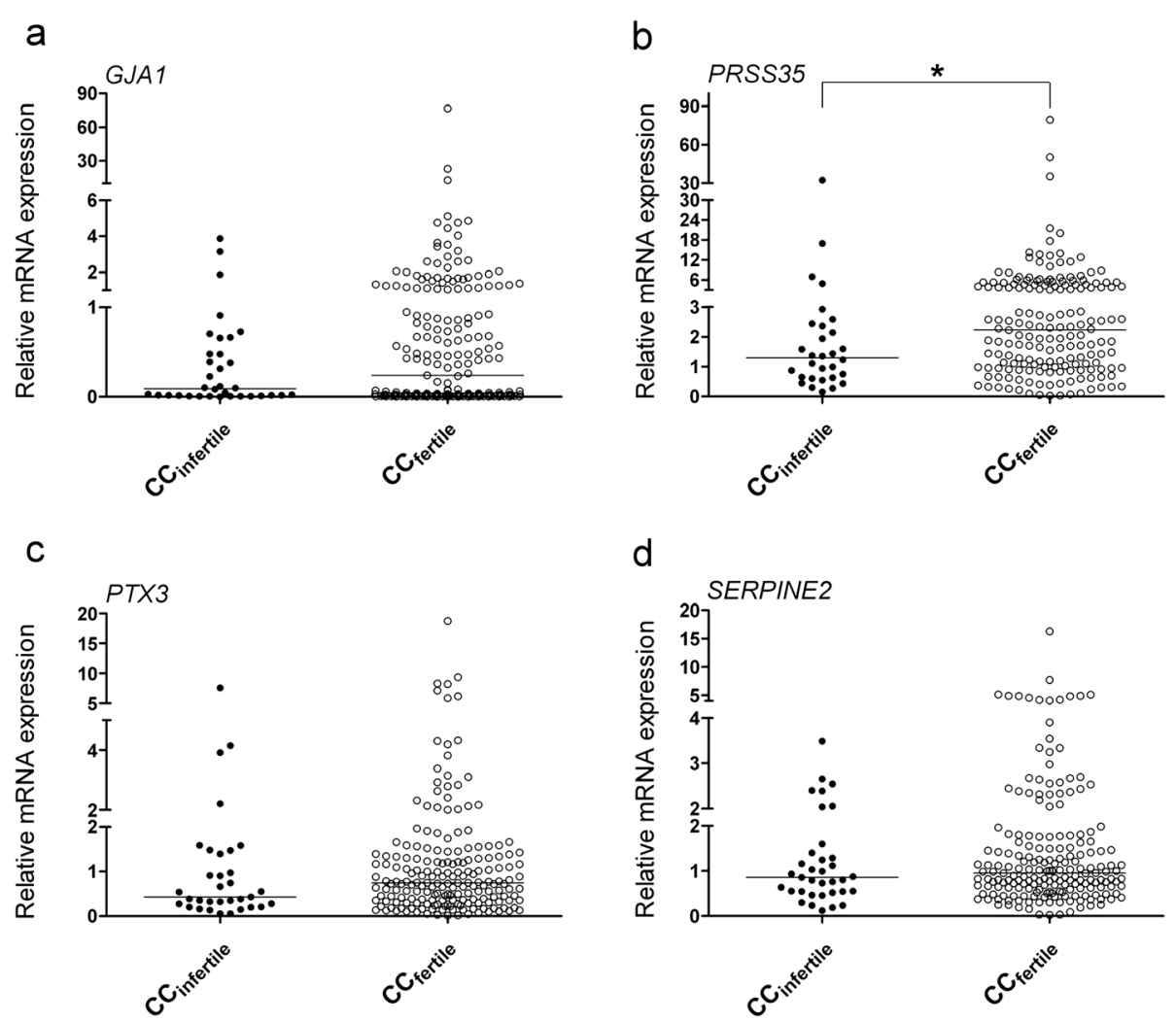

Fig. 3 Relative mRNA levels of GJA1 (a), PRSS35 (b), PTX3 (c), and SERPINE2 (d) in cumulus cells of fertilized and unfertilized oocytes, as revealed by qRT-PCR. ${ }^{*} P<0.05$

was also reported to be significantly higher in pregnant patients [17].

SERPINE2 mRNA levels in cumulus cells are associated with oocyte maturation, with a significantly lower level in mature oocytes [24, 25]. This correlation was verified in our study (Fig. 2) using a larger sample cohort. In a mouse animal model, higher levels of SERPINE2 were demonstrated to impair cumulus expansion and oocyte maturation [25]. Although SERPINE2 showed a trend toward a higher expression in cumulus cells of oocytes developing into good embryos than in cumulus cells of oocytes developing into poor embryos (Fig. 4), the difference was not significant between the two groups. Nevertheless, SERPINE2 mRNA levels were significantly higher in granulosa cells collected from follicles that resulted in pregnancy [18].

Our data revealed that PRSS35 mRNA levels are associated with oocyte fertilization potential (Fig. 2). This is the first report demonstrating a relationship between human PRSS35 expression and oocyte competence. Prss35-null mice have no defects in female fertility, suggesting that the gene is dispensable for murine fertility and embryo development [33]. However, this remains unclear in case of humans. Diao et al. did not detect any compensatory upregulation of other proteases reported in the uterus; however, the expression of other protease-related genes cannot be ruled out [33]. Alternatively, other compensatory effects may exist in Prss35 knockout mice as PRSS35 may not possess any serine protease activity because the amino acids in its protease catalytic active site are changed. A study employing knockout mice lacking specific proteases that cause some unexpected results in the ovulatory process because of redundancy and overlapping functions has also been conducted previously [34].

While the expression of PTX3 has been reported to be significantly lower in cumulus cells from immature oocytes than in those from mature oocytes [15], our data showed no significant difference (Fig. 2c). Pooled cumulus cells from fertilized oocytes were found to have 3- to 12-fold increases in PTX3 levels than those from unfertilized oocytes [14]; however, the cumulus cells collected from individual COC in our study showed no significant difference. Congruent with previous reports $[10,20]$, we found that cumulus PTX3 mRNA levels were not associated with the embryo morphological grade.

Selecting embryos with good morphology for transplanting has proved to be correlated with a good pregnancy outcome [35]. Our results showed that expression levels of GJA1, PRSS35, PTX3, and SERPINE2 did not differ significantly between cumulus cells of embryos 

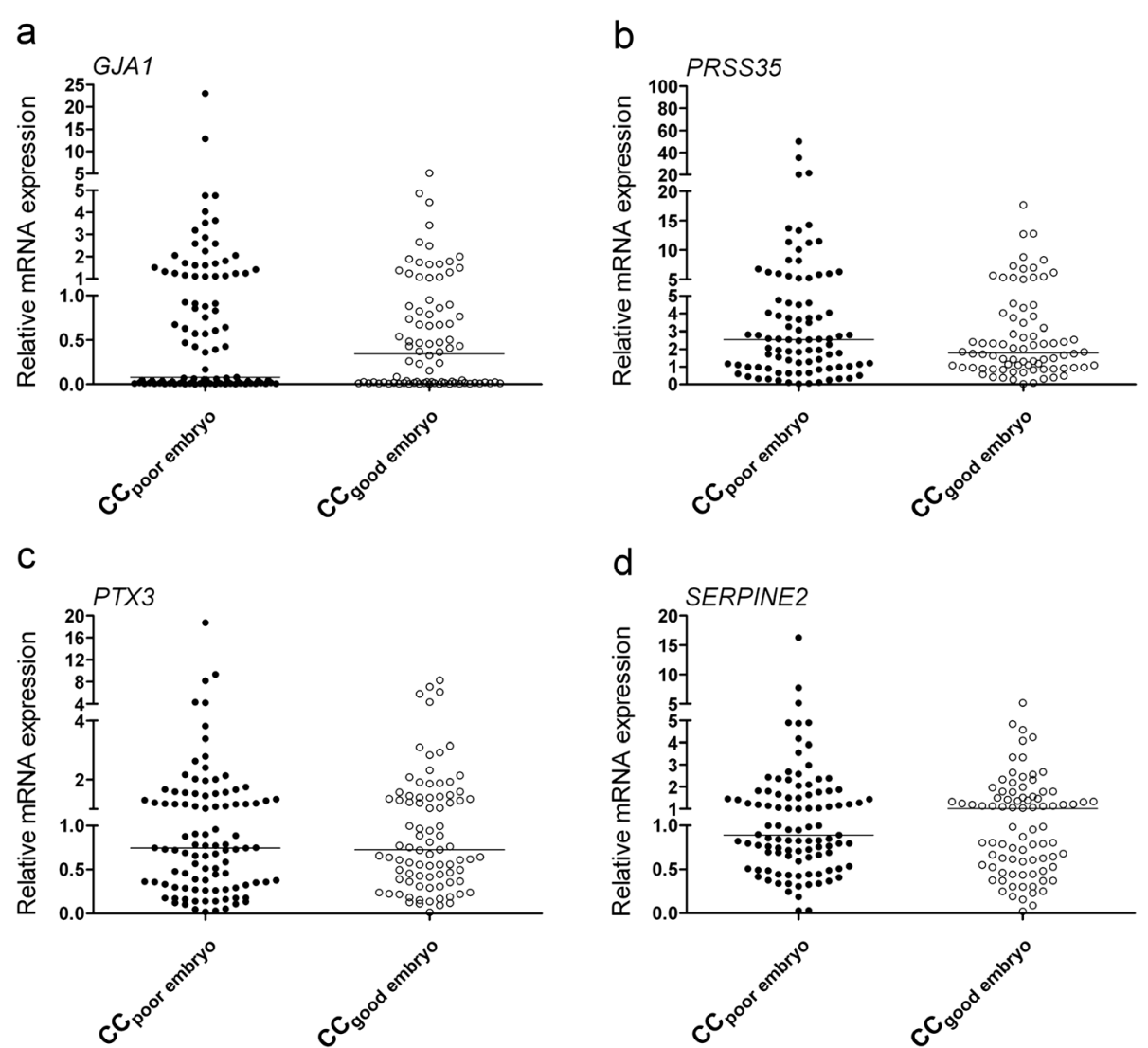

Fig. 4 qRT-PCR revealed the relative mRNA levels of GJA1 (a), PRSS35 (b), PTX3 (c), and SERPINE2 (d) in cumulus cells collected from oocytes developing into embryos with good or poor morphology

with good and poor morphology, indicating that these genes may not be used as marker genes for predicting early embryo development.

Comparison of cumulus gene expression of pregnant and nonpregnant embryo, which is the transfer of a single embryo, would be a good strategy for revealing good marker genes. Using the single embryo transfer (SET) strategy, several studies have proposed marker genes for pregnancy outcome [20,36-38].

This study has some limitations: the controlled ovarian hyperstimulation procedure produces more mature oocytes than immature oocytes, and the ICSI treatment results in few unfertilized oocytes; thus, the sample size of immature oocyte or unfertilized oocyte is always small in this type of study, as seen previously [10, 12, 15, 16]. In addition, dead and arrested embryos are also found. Although cumulus cells that developed into good or poor embryos showed significantly higher GJA1 mRNA levels than those that developed into arrested embryos (data not shown), the sample size was relatively less because of the unavailability of arrested embryos. Furthermore, this kind of study often produces contradictory results (e.g., GJA1 and PTX3 cases mentioned above). The cumulus expression of EFNB2, RGS2, and $V C A N$, which are proposed as biomarkers of pregnancy $[19,20,36-38]$, was also inconsistent as revealed in a recently published report [39].

The selection of embryos with higher developmental potential has been one of the major challenges in assisted reproductive technology (ART). Because cumulus cells are discarded in ART, the cumulus samples have the advantage of being noninvasively collected. Although cumulus gene expression may represent a promising method compared with the currently used morphology-based method, more investigations are warranted. Thus, a prospective larger cohort study or the use of SET cumulus samples remains necessary to clarify the effectiveness.

In summary, GJA1 and SERPINE2 represent gene markers potentially associated with oocyte maturation, and PRSS35 may be correlated with oocyte fertilization ability. GJA1, PRSS35, PTX3, and SERPINE2 may not be considered as markers for predicting early embryo development.

\section{Competing interests}

The authors declare that they have no competing interests.

\section{Authors' contributions}

SHL participated in the design of the study and drafted the original manuscript. MHL and YMH contributed to sample collection and data analysis. CHL and LYY conducted GPCR experiments and contributed to data 
analysis. YJC helped in sample collection. RKKL conceived the study and participated in project design and coordination. All authors read and approved the final manuscript.

\section{Acknowledgments}

This work was supported by the grants from the National Science Council, Taiwan (NSC 101-2314-B-195-009-MY3) and Mackay Memorial Hospital, Taiwan (MMH 10216, 10306, and 10402).

\section{Author details}

'Department of Medical Research, Mackay Memorial Hospital, Tamsui District, New Taipei City 251, Taiwan. ${ }^{2}$ Mackay Junior College of Medicine, Nursing, and Management, Beitou District, Taipei City 112, Taiwan. ${ }^{3}$ Graduate Institute of Biochemical and Biomedical Engineering, National Taipei University of Technology, Taipei City 106, Taiwan. ${ }^{4}$ Department of Obstetrics and Gynecology, Mackay Memorial Hospital, Taipei City 104, Taiwan. ${ }^{5}$ Mackay Medical College, Sanzhi District, New Taipei City 252, Taiwan. ${ }^{6}$ Department of Obstetrics and Gynecology, Taipei Medical University, Taipei City 110, Taiwan.

Received: 4 June 2015 Accepted: 6 August 2015

Published online: 16 August 2015

\section{References}

1. Gui LM, Joyce IM. RNA interference evidence that growth differentiation factor-9 mediates oocyte regulation of cumulus expansion in mice. Biol Reprod. 2005;72:195-9.

2. Su YQ, Wu X, O'Brien MJ, Pendola FL, Denegre JN, Matzuk MM, et al. Synergistic roles of BMP15 and GDF9 in the development and function of the oocyte-cumulus cell complex in mice: genetic evidence for an oocyte-granulosa cell regulatory loop. Dev Biol. 2004;276:64-73.

3. Yokoo M, Sato E. Cumulus-oocyte complex interactions during oocyte maturation. Int Rev Cytol. 2004;235:251-91.

4. Salustri A, Garlanda C, Hirsch E, De Acetis M, Maccagno A, Bottazzi B, et al. PTX3 plays a key role in the organization of the cumulus oophorus extracellular matrix and in in vivo fertilization. Development. 2004;131:1577-86.

5. Varani S, Elvin JA, Yan C, DeMayo J, DeMayo FJ, Horton HF, et al. Knockout of pentraxin 3, a downstream target of growth differentiation factor-9, causes female subfertility. Mol Endocrinol. 2002;16:1154-67.

6. Kidder GM, Mhawi AA. Gap junctions and ovarian folliculogenesis. Reproduction. 2002;123:613-20

7. Eppig JJ. Oocyte control of ovarian follicular development and function in mammals. Reproduction. 2001;122:829-38.

8. Matzuk MM, Burns KH, Viveiros MM, Eppig JJ. Intercellular communication in the mammalian ovary: oocytes carry the conversation. Science. 2002;296:2178-80

9. Assou S, Haouzi D, Mahmoud K, Aouacheria A, Guillemin Y, Pantesco V, et al. A non-invasive test for assessing embryo potential by gene expression profiles of human cumulus cells: a proof of concept study. Mol Hum Reprod. 2008;14:711-9.

10. Cillo F, Brevini TA, Antonini S, Paffoni A, Ragni G, Gandolfi F. Association between human oocyte developmental competence and expression levels of some cumulus genes. Reproduction. 2007;134:645-50.

11. McKenzie LJ, Pangas SA, Carson SA, Kovanci E, Cisneros P, Buster JE, et al. Human cumulus granulosa cell gene expression: a predictor of fertilization and embryo selection in women undergoing IVF. Hum Reprod. 2004;19:2869-74

12. Feuerstein P, Cadoret V, Dalbies-Tran R, Guerif F, Bidault R, Royere D. Gene expression in human cumulus cells: one approach to oocyte competence. Hum Reprod. 2007;22:3069-77.

13. van Montfoort AP, Geraedts JP, Dumoulin JC, Stassen AP, Evers JL, Ayoubi TA. Differential gene expression in cumulus cells as a prognostic indicator of embryo viability: a microarray analysis. Mol Hum Reprod. 2008;14:157-68.

14. Zhang X, Jafari N, Barnes RB, Confino E, Milad M, Kazer RR. Studies of gene expression in human cumulus cells indicate pentraxin 3 as a possible marker for oocyte quality. Fertil Steril. 2005;83 Suppl 1:1169-79.

15. Anderson RA, Sciorio R, Kinnell H, Bayne RA, Thong KJ, de Sousa PA, et al. Cumulus gene expression as a predictor of human oocyte fertilisation, embryo development and competence to establish a pregnancy. Reproduction. 2009;138:629-37.
16. Hasegawa J, Yanaihara A, Iwasaki S, Mitsukawa K, Negishi M, Okai T. Reduction of connexin 43 in human cumulus cells yields good embryo competence during ICSI. J Assist Reprod Genet. 2007;24:463-6.

17. Wang HX, Tong D, El-Gehani F, Tekpetey FR, Kidder GM. Connexin expression and gap junctional coupling in human cumulus cells: contribution to embryo quality. J Cell Mol Med. 2009;13:972-84.

18. Hamel M, Dufort I, Robert C, Gravel C, Leveille MC, Leader A, et al. Identification of differentially expressed markers in human follicular cells associated with competent oocytes. Hum Reprod. 2008;23:1118-27.

19. Hamel M, Dufort I, Robert C, Leveille MC, Leader A, Sirard MA. Genomic assessment of follicular marker genes as pregnancy predictors for human IVF. Mol Hum Reprod. 2010;16:87-96.

20. Gebhardt KM, Feil DK, Dunning KR, Lane M, Russell DL. Human cumulus cell gene expression as a biomarker of pregnancy outcome after single embryo transfer. Fertil Steril. 2011;96:47-52. e42.

21. Carabatsos MJ, Sellitto C, Goodenough DA, Albertini DF. Oocyte-granulosa cell heterologous gap junctions are required for the coordination of nuclear and cytoplasmic meiotic competence. Dev Biol. 2000;226:167-79.

22. Simon AM, Goodenough DA, Li E, Paul DL. Female infertility in mice lacking connexin 37. Nature. 1997;385:525-9.

23. Li TY, Colley D, Barr KJ, Yee SP, Kidder GM. Rescue of oogenesis in Cx37-null mutant mice by oocyte-specific replacement with Cx43. J Cell Sci. 2007:120:4117-25.

24. Devjak R, Fon Tacer K, Juvan P, Virant Klun I, Rozman D, Vrtacnik Bokal E. Cumulus cells gene expression profiling in terms of oocyte maturity in controlled ovarian hyperstimulation using $\mathrm{GnRH}$ agonist or $\mathrm{GnRH}$ antagonist. PLoS One. 2012;7:e47106.

25. Lu CH, Lee RK, Hwu YM, Lin MH, Yeh LY, Chen YJ, et al. Involvement of the serine protease inhibitor, SERPINE2, and the urokinase plasminogen activator in cumulus expansion and oocyte maturation. PLoS One. 2013;8:e74602.

26. Wahlberg P, Nylander A, Ahlskog N, Liu K, Ny T. Expression and localization of the serine proteases high-temperature requirement factor $A 1$, serine protease 23 , and serine protease 35 in the mouse ovary. Endocrinology. 2008; 149:5070-7.

27. Yang WJ, Hwu YM, Lee RK, Li SH, Fleming S. Early-cleavage is a reliable predictor for embryo implantation in the $\mathrm{GnRH}$ agonist protocols but not in the GnRH antagonist protocols. Reprod Biol Endocrinol. 2009; $7: 20$

28. Scholtes MC, Zeilmaker GH. A prospective, randomized study of embryo transfer results after 3 or 5 days of embryo culture in in vitro fertilization. Fertil Steril. 1996;65:1245-8.

29. Veeck LL. Preembryo grading and degree of cytoplasmic fragmentation. In: Veeck LL, editor. An Atlas of Human Gametes and Conceptuses: An Illustrated Reference for Assisted Reproductive Technology. New York: Parthenon; 1999. p. 46-51.

30. Livak KJ, Schmittgen TD. Analysis of relative gene expression data using real-time quantitative PCR and the 2(-Delta Delta C(T)) Method. Methods. 2001;25:402-8.

31. Ekart J, McNatty K, Hutton J, Pitman J. Ranking and selection of MII oocytes in human ICSI cycles using gene expression levels from associated cumulus cells. Hum Reprod. 2013;28:2930-42.

32. Edry I, Sela-Abramovich S, Dekel N. Meiotic arrest of oocytes depends on cell-to-cell communication in the ovarian follicle. Mol Cell Endocrinol. 2006;252:102-6.

33. Diao H, Xiao S, Li R, Zhao F, Ye X. Distinct spatiotemporal expression of serine proteases Prss 23 and Prss 35 in perimplantation mouse uterus and dispensable function of Prss35 in fertility. PLoS One. 2013;8:e56757.

34. Leonardsson G, Peng XR, Liu K, Nordstrom L, Carmeliet P, Mulligan R, et al. Ovulation efficiency is reduced in mice that lack plasminogen activator gene function: functional redundancy among physiological plasminogen activators. Proc Natl Acad Sci U S A. 1995;92:12446-50.

35. Loutradis D, Drakakis $P$, Kallianidis K, Milingos $S$, Dendrinos $S$, Michalas $S$. Oocyte morphology correlates with embryo quality and pregnancy rate after intracytoplasmic sperm injection. Fertil Steril. 1999;72:240-4.

36. Feuerstein P, Puard V, Chevalier C, Teusan R, Cadoret V, Guerif F, et al. Genomic assessment of human cumulus cell marker genes as predictors of oocyte developmental competence: impact of various experimental factors. PLoS One. 2012;7:e40449.

37. Wathlet $\mathrm{S}$, Adriaenssens $\mathrm{T}$, Segers I, Verheyen G, Janssens R, Coucke W, et al. New candidate genes to predict pregnancy outcome in single embryo 
transfer cycles when using cumulus cell gene expression. Fertil Steril. 2012;98:432-9. e431-434.

38. Wathlet S, Adriaenssens T, Segers I, Verheyen G, Van Landuyt L, Coucke W, et al. Pregnancy prediction in single embryo transfer cycles after ICSI using QPCR: validation in oocytes from the same cohort. PLoS One. 2013;8:e54226.

39. Burnik Papler T, Vrtacnik Bokal E, Maver A, Lovrecic L. Specific gene expression differences in cumulus cells as potential biomarkers of pregnancy. Reprod Biomed Online. 2015;30:426-33.

Submit your next manuscript to BioMed Central and take full advantage of:

- Convenient online submission

- Thorough peer review

- No space constraints or color figure charges

- Immediate publication on acceptance

- Inclusion in PubMed, CAS, Scopus and Google Scholar

- Research which is freely available for redistribution 